\title{
A TRADIÇÃO E A LINGUAGEM COMO CONDIÇÃO DE POSSIBILIDADE À PERSPECTIVA UNIVERSAL E MULTICULTURAL DOS DIREITOS HUMANOS
}

Wilson Engelmann

\section{RESUMO}

É objetivo deste trabalho investigar a importância do tempo, especialmente a partir dos diversos estágios propostos por François Ost. A sua análise é enriquecida mediante as contribuições da hermenêutica de Martin Heidegger e Hans-Georg Gadamer. No contexto assim delineado, pretende-se mostrar que a linguagem é condição de possibilidade para absorver essa tradição para projetar a universalidade e o multiculturalismo próprios dos Direitos Humanos, notadamente na sua projeção no Século XXI.

Palavras-chave: Direitos Humanos. Hermenêutica Filosófica. Linguagem. Multiculturalismo. Tradição. Universalismo.

\section{INTRODUÇÃO}

O mundo, no início deste Século XXI, tem vários desafios, alguns especialmente ligados às pessoas e a preservação do gênero humano. Para tanto, torna-se necessária a discussão acerca dos Direitos Humanos e como as conquistas já sedimentadas poderão ser ampliadas, valorizando a tradição já acumulada, especialmente por meio de sofrimento e reflexão. Propõe-se, portanto, investigar a linguagem como condição de possibilidade para alargar e consolidar as conquistas realizadas em nome dos Direitos Humanos, trazendo à luz a fala da tradição.

Não se pensa num simples aspecto retórico, mas em pressupostos focados numa igualdade material entre as pessoas, com o respeito das diferenças que the são inerentes. Por isso, a preocupação deste estudo é buscar alternativas para a concretização dos Direitos Humanos, eis que no plano teórico o seu desenvolvimento já está desde há muito consolidado.

\section{O TEMPO E O DIREITO: A HERMENÊUTICA DA TRADIÇÃO NA ESTRUTURA DOS DIREITOS HUMANOS.}

Quando Heidegger apresenta o tempo e sua relação com o ser, alerta: 
o tempo não é uma multiplicidade de agoras justapostos, porque cada agora já não é em cada agora e porque faz parte do tempo a notável extensão, em ambos os lados, para dentro do não-ser. $O$ agora não está associado a um ponto fixo como ponto e, portanto, não pode fazer parte dele, pois é, segundo sua essência, princípio e fim. No agora como tal já se encontra a remissão ao não-mais e ao ainda-não. ${ }^{1}$

O ponto principal dessa passagem é que o tempo não significa uma mera organização de agoras, pois eles significam momentos, vinculados ao passado ("não-mais"), presente (gegenwart) ou futuro ("ainda-não"), recebendo atribuição de sentido pelo contexto (mundo circundante), onde a pré-compreensão exerce um papel importante, responsável por trazer de volta o vigor de ter sido em seu sentido mais próprio.

Uma leitura atual das interfaces desses diversos estágios do tempo é realizada por François Ost, em sua obra intitulada "O Tempo do Direito", onde a valorização do passado no presente será fundamental para se construir uma sociedade global e multicultural em condições de respeitar cada pessoa com as suas características. Com isso, será viável projetar um futuro no presente com capacidade para a prática da proteção efetiva dos Direitos Humanos.

O primeiro estágio desta proposta de estudar o tempo está reservado à memória que é responsável por ligar o passado, a fim de descobrir as suas contribuições para a realização da tarefa de compreensão dos fatos da vida do presente. O passado é construído a partir do presente, revelando-se o seu aspecto criativo e ativo. ${ }^{2} \mathrm{O}$ presente mostra-se como um "locus" privilegiado para captar a riqueza da pré-compreensão, formada com a interferência dos eventos ocorridos no passado. Vale dizer, a compreensão se dará a partir do contexto histórico onde se está desde sempre inserido. Esse material é organizado a partir do ato de ligação estabelecido com o passado, buscando nele os ingredientes necessários para uma efetiva aplicação dos Direitos Humanos.

Nesse processo, a tradição surge como um elemento de singular importância, pois é o "centro de uma temporalidade que pretende 'ligar o passado". Dessa forma, a tradição pode ser considerada como o "elo lançado entre as épocas, essa continuidade viva da transmissão de crenças e de práticas"3 A tradição é, portanto, a nominação do ato de valorar as contribuições oriundas do passado.

Para explorar o modo de formação da tradição, que surge como o elo de vinculação dos acontecimentos anteriores, Maclntyre aponta três estágios detectados na formação e desenvolvimento de uma tradição: o primeiro estágio é aquele onde "as crenças, textos e autoridades relevantes ainda não foram questionados". Parece que nesse momento temos o ponto de partida da formação da memória, numa nítida interação entre o individual e o coletivo (social). $O$ segundo estágio está vinculado a uma releitura do primeiro estágio, constatando- 
se a necessidade de realizar seleções, dadas as inadequações que foram identificadas, mas sem indicativo de solução.

Trata-se, nesse caso, de constatar o caráter ativo e voluntário da memória que permite opção, escolha de fatos considerados relevantes para a compreensão do presente. É um olhar seletivo do presente lançado sobre o passado, mas sem deliberação. Esta ocorrerá no terceiro estágio, "no qual a reação a tais inadequações resultou numa série de reformulações, reavaliações, novas formulações e avaliações concebidas, a fim de solucionar as inadequações e superar limitações". ${ }^{4}$

Esse terceiro estágio privilegia determinados fatos em detrimento de outros, dadas as suas repercussões na atualidade. Aqui deverá ingressar a necessária reflexão sobre a falta de aplicação das teorias geradas em torno do tema dos direitos do homem.

Nesse processo sucessivo de sedimentação de fatos do passado, inscrevese a matéria relativa aos Direitos Humanos. Como componente da consciência comum dos integrantes dos grupos sociais, respeitadas as suas particularidades, os Direitos Humanos fazem parte da tradição local e internacional, posto fruto de um processo histórico consubstanciado nas perspectivas jusnaturalista, universalista e constitucional. A preocupação que o tema carrega transmite uma tradição humana de lutas, conquistas e retrocessos na busca por uma vida digna.

Segundo Ost, o Direito é tradição por excelência, na medida em que "constitui-se por sedimentações sucessivas de soluções, e as próprias novidades que ele produz derivam de forma genealógica de argumentos e de razões dignos de crédito num ou noutro momento do passado." $\mathrm{O}$ caráter histórico do Direito, e com ele dos Direitos Humanos, é oriundo da junção de todo um conjunto de decisões, envolvendo situações humanas que devem servir para alimentar a précompreensão, visando explicitar o desenho de soluções que efetivamente tenham como foco principal o humano.

Portanto, "a tradição é imediatamente caracterizada por dois aspectos: a continuidade e a conformidade. Por um lado, há ligação a uma dada fonte de anterioridade; por outro, existe alinhamento num determinado foco de autoridade. A tradição é uma anterioridade que constitui autoridade". ${ }^{6}$ Não se trata de uma autoridade que impõe determinado ponto de vista. Pelo contrário, é uma autoridade formada pelo sucessivo aprendizado das gerações anteriores, prontas a servir de fonte de ensinamento e aconselhamento para a solução de casos no presente. Surge, assim, o espaço fértil para o ingresso da tarefa da hermenêutica que

não é desenvolver um procedimento da compreensão, mas esclarecer as condições sob as quais surge compreensão. Mas essas condições não têm todas o modo de ser de um 'procedimento' ou de um método de tal modo que quem compreende poderia aplicá-las por si mesmo - essas condições têm de estar dadas. ${ }^{7}$ 
A compreensão será a responsável pela distinção entre os preconceitos verdadeiros dos falsos que o intérprete possui e aqueles que vêm ao seu encontro. Nesse particular, surge a importância do tempo e o seu significado para a compreensão. É a experiência, onde o intérprete encontra-se jogado, o aspecto peculiar de tempo que será fundamental para a construção do processo de compreensão, interpretação e aplicação de regras e princípios capazes de proteger os direitos dos humanos, seja contra as investidas do próprio Estado ou de organizações particulares, especialmente aquelas formadas a partir dos avanços dos efeitos da globalização. Apesar disso, a tradição não fornece uma fórmula pronta e acabada, mas que precisa ser revisada e adaptada em cada nova situação.

Assim, Gadamer refere o efetivo significado da chamada "distância temporal" para o desenvolvimento da compreensão:

\begin{abstract}
O tempo não é um precipício que devamos transpor para recuperarmos o passado; é, na realidade, o solo que mantém o devir e onde o presente cria raízes. [...] Trata-se, na verdade, de considerar a 'distância temporal' como fundamento de uma possibilidade positiva e produtiva de compreensão. Não é uma distância a percorrer, mas uma continuidade viva de elementos que se acumulam formando a tradição, isto é, uma luz à qual tudo o que trazemos conosco de nosso passado, tudo o que nos é transmitido faz a sua aparição. ${ }^{8}$
\end{abstract}

Resta sublinhada a importância do passado para a construção da compreensão, que na sua constituição procura resgatar os caminhos anteriormente percorridos, que formam a sua condição de possibilidade. Este passado é o responsável pela formação dos preconceitos, alimentando-os e condicionando-os.

Além disso, somente se pode compreender o presente mediante os legados oriundos do passado. Gadamer justamente quer mostrar que os fatos que compõem o passado não formam um conjunto que se torna objeto da consciência. Pelo contrário, é uma bagagem na qual nos movemos e participamos, não a recebemos acabada. "A tradição não se coloca, pois, contra nós; ela é algo em que nos situamos e pelo qual existimos; em grande parte é um meio tão transparente que nos é invisível - tão invisível como a água o é para o peixe". ${ }^{9}$ É por isso que Gadamer afirma que nós pertencemos à história, estamos imersos na tradição e dela buscamos subsídios para a compreensão do mundo circundante, atribuindo-Ihe sentido.

Nessa mesma linha se pode dizer que "o essencial na tradição é, pois, a autoridade reconhecida ao passado para regular, ainda hoje, as questões do presente". ${ }^{10} O$ ato de ligar 0 passado encontra-se circunscrito a essa particularidade: a memória da tradição exerce uma autoridade sobre o presente, na medida em que vem ao nosso encontro, como um modo de compreender a realidade atual. Aí a sua autoridade. Trata-se de uma autoridade consolidada pelo tempo e não artificialmente imposta pela vontade individual de um governante. 
Convém observar o caráter criativo do processo de inserção da tradição (responsável por forjar a pré-compreensão) no círculo hermenêutico: "o enigma e a força da tradição é renovar sempre o fio da continuidade, ao mesmo tempo em que incorpora a inovação e reinterpretação que o presente exige: a herança é incessantemente modificada e, contudo, é da mesma herança que se trata". ${ }^{11} \mathrm{Em}$ decorrência das diversas faces produzidas pela matéria dos Direitos Humanos, torna-se necessário valorizar os legados da tradição, mas com abertura suficiente para receber as adaptações produzidas pelos movimentos do presente.

O segundo compasso do tempo projetado por François Ost refere-se ao perdão como um meio para desligar o passado, no sentido de abrir o tema dos Direitos Humanos às inovações e aos novos desafios próprios de cada época.

Nesse momento, chega-se ao estágio anteriormente descrito a partir de Macintyre, a saber, é momento de avaliar criticamente a tradição, aferindo-se inadequações e pontos a serem ajustados. Não se trata, no entanto, de acabar com a tradição,

mas submetê-la a um processo permanente, crítico e reflexivo, de revisão que, ao mesmo tempo lhe assegure uma consciência mais exata da sua singularidade e lhe facilite uma abertura dialógica com as outras tradições num espaço público de discussão - científico, artístico ou político - que está em grande parte por construir. ${ }^{12}$

A abertura desse espaço destina-se a construir releituras da tradição e promover a interação entre as diversas tradições produzidas no contexto social, visando ao enriquecimento recíproco. O combate à concepção metodológica da hermenêutica, tanto em Heidegger quanto em Gadamer, funda-se nesse aspecto: a mobilidade e a finitude da existência humana. ${ }^{13}$ Valorar a tradição não significa curvar-se a determinado aspecto sem questionamento. Pelo contrário, a tradição fornece o substrato para efetivar leituras adequadas às necessidades de cada época histórica, humanamente produzidas e, com isso, nunca iguais, e sempre finitas, como a vida de cada homem e mulher. Portanto, assim se opera o encontro das idéias de François Ost e Martin Heidegger, pois o passado, como "vigor de ter sido"14, não significa algo que ficou ultrapassado e deve ser esquecido: é um passado que continua irradiando projeções valorizáveis.

O terceiro momento está preocupado com a promessa, chamada a ligar o futuro. O homem, como não domina o futuro, projeta promessas e pontes para frente, para o desconhecido, abrindo-se novos desafios. Os Direitos Humanos, ao trabalharem com a finitude da existência humana, procuram conjugar e encontrar o ponto de equilíbrio entre "a emancipação dos homens com o estabelecimento da lei". ${ }^{15}$ A garantia da liberdade para a existência humana digna é o grande compromisso de trabalho com o tema dos Direitos Humanos. Quando Ost fala na "lei" aponta para o desenvolvimento de regras de conduta, internacionalmente aceitas e nacionalmente vinculantes, que protejam os humanos, garantindo-Ihes 0 atendimento de suas necessidades. 
Com o desafio assim delineado, surge novamente a questão da necessidade de revisar antigas e anteriores concepções e teorias, pois "é preciso saber rever para durar". ${ }^{16}$ Aí a chave da sobrevivência dos direitos já conquistados a título de Direitos Humanos: revisar, criar e adaptar são palavras indispensáveis ao equacionamento do tempo e dos Direitos Humanos. Pode-se fazer, a partir dessas constatações, uma vinculação com a idéia de Heidegger de que a interpretação é o modo de conhecer as possibilidades lançadas pela compreensão. Como esta não ocorre sempre da mesma forma, pois o mundo circundante não é sempre o mesmo, deve-se estar aberto à revisão das interpretações já lançadas. ${ }^{17}$

$\mathrm{Na}$ medida em que se projeta o olhar para o futuro, descobre-se a perspectiva da ética, perpassada pela "fides" romana, enquanto "fé" colocada na base dos compromissos sociais da esfera pública como a lei e o julgamento, assim como na esfera privada, nos contratos e convenções, por exemplo. No caso, precisamos estar preocupados em resgatar e valorizar a fé, a crença nas promessas lançadas na instalação do Estado Democrático de Direito.

Assim, não se trata mais de uma projeção apenas vinculada à vontade individual do soberano. Pelo contrário, a preocupação está voltada a uma ordem jurídica compreendida "como um sistema durável de interações e de compromissos recíprocos baseados na confiança". ${ }^{18}$ Vale lembrar que a confiança foi o elemento motivador da "celebração" do contrato social, o qual, em última análise, é o responsável pela atual forma do Estado. Desta maneira, os humanos precisam confiar nas promessas públicas, especialmente no tocante ao respeito e proteção dos seus direitos (direitos dos humanos).

Aliás, independente da justificativa, esses direitos devem ser considerados elementares para a caracterização de qualquer agrupamento social. Isso poderá ser resumido na seguinte fórmula: "a promessa compromete o futuro se, e apenas se, conseguir apoiar-se numa forma prévia de confiança que ao mesmo tempo regenera e reforça". ${ }^{19} \mathrm{O}$ ato de ligar o futuro significa lançar uma promessa que consiga, pela intermediação da "boa-fé", respeito e credibilidade. Caso contrário, não será possível projetar raízes concretas para frente, pois os elos formados serão extremamente frágeis e instáveis.

Com isso, desenha-se o seguinte desafio para a proteção dos Direitos Humanos: "pensar as vias de abertura do futuro em formas duráveis; romper com o passado, apoiando-se ao mesmo tempo nele, libertar as forças instituintes nas próprias formas do instituído". ${ }^{20}$ As promessas lançadas para o futuro deverão estar alicerçadas nas forças produzidas pelo passado e reinterpretadas no presente. Desenha-se, assim, a chave para a caracterização da confiança nas promessas. Não havendo essas linhas de vinculação, tratar-se-ão de meras promessas ou teorias, sem nenhuma preocupação com o seu efetivo cumprimento. 
O futuro nutre-se da pré-estrutura (Heidegger) ou da pré-compreensão (Gadamer) formada mediante o aproveitamento das circunstâncias produzidas pelo passado - memória e tradição: "a hermenêutica deve partir do fato de que quem quer compreender está ligado à coisa que vem à fala na tradição, mantendo ou adquirindo um vínculo com a tradição a partir de onde fala o texto transmitido". ${ }^{21}$ Os Direitos Humanos podem ser considerados promessas, originadas na tradição de cada povo, que projetam possibilidades para a manutenção e o desenvolvimento dos diversos grupos sociais.

O quarto momento proposto por François Ost encontra-se vinculado ao requestionamento, onde se torna possível desligar o futuro. $O$ requestionamento do tempo poderá ser vislumbrado sob diversas formas, a saber, "adaptar o texto às circunstâncias variáveis, submetê-los regularmente à avaliação, enriquecê-lo com precisões jurisprudenciais e doutrinais". ${ }^{22}$ Em todas essas etapas, a partir de novas luzes lançadas pelo passado e as contingências do presente e do futuro, permite-se revisar concepções já projetadas, justamente para atender na integralidade às promessas lançadas anteriormente. $O$ requestionamento acompanha toda a evolução do tempo, não sendo necessariamente lançado para o final.

Quando se apresenta o futuro, não se propõe o amanhã, mas o hoje preocupado com a continuidade do humano. Com isso, abre-se espaço para o viver a atualidade, ou seja, o "tempo real". Não se trata mais de um tempo de "duração, da expectativa, do projeto paciente e da longa memória. Radicalmente acelerado, é reconduzido do longo prazo ao curso prazo, e deste ao imediato". ${ }^{23} \mathrm{~A}$ apresentação atual do tempo com esse perfil acaba provocando uma inversão temporal, separando-nos do poder integrador e alimentador do passado, a saber, da tradição, e afastando a nossa capacidade de projetar, de planejar, de mobilizar o futuro.

Vale dizer, o movimento da urgência esquece o encadeamento dos diversos compassos do tempo: "vindo-a-si mesma num porvir, a decisão se atualiza na situação. $O$ vigor de ter sido surge do porvir de tal maneira que o porvir do ter sido (melhor, em vigor) deixa vir-a-si a atualidade. Chamamos de temporalidade este fenômeno unificador do porvir que atualiza o vigor de ter sido". ${ }^{24}$ Cabe sublinhar que "o nosso universo é o dos programas curtos, das mudanças perpétuas de normas e dos estímulos a experimentar sem esperar qualquer nova sugestão". ${ }^{25}$ Esquecemos que a temporalidade (temporal + idade) é um demorar-se, o que significa verificar as diversas possibilidades projetadas pela pré-compreensão, oriunda da tradição.

Esse é o desafio vivido pelos Direitos Humanos, a preocupação com o imediato e o consumo fácil, acaba colocando em risco a sua manutenção. Nem se pode falar em sua aplicação. Nesse sentido, a reflexão sobre o tempo é fundamental para o tema, pois dele depende a sobrevivência da própria espécie humana que vai aperfeiçoando a sua existência, justamente na promoção dos Direitos Humanos. 
Provavelmente, um dos motivos dessa derrocada dos Direitos Humanos resida na visão equivocada do tempo: "o tempo não é primeiramente um abismo que se deve ultrapassar porque separa e distancia. É na verdade o fundamento sustentador do acontecer, onde se enraíza a compreensão atual. Desse modo, a distância temporal não é algo que deva ser superado". ${ }^{26} \mathrm{O}$ equívoco precisa ser repensado, sob pena do ser humano estar correndo sério risco de sucumbência a uma mera concepção econômica das relações projetadas pelas redes da globalização, que são caracterizadas pela preocupação com o "tempo real". Aqui se abre o espaço para o requestionamento em relação aos Direitos Humanos. Portanto, é preciso situá-los entre o "tempo real" e o "tempo diferido" e o projeto que desloca o foco da sua fundamentação a uma aplicação efetiva.

\section{A LINGUAGEM COMO CONDIÇÃO DE POSSIBILIDADE À PERSPECTIVA UNIVERSAL E MULTICULTURAL DOS DIREITOS HUMANOS}

O enlaçamento destes diversos estágios temporais é realizado pela linguagem. Ela também mostra que não existe "um abismo" entre um e outro. Eles estão próximos uns dos outros e de cada pessoa, pois representam o seu mundo circundante. É a linguagem que possibilita o acesso aos estágios, a fim de retirarse deles os ingredientes para a consolidação da estrutura do círculo hermenêutico que sustenta a atribuição de sentido dos diversos contornos dos Direitos Humanos.

Na proposta da filosofia hermenêutica de Heidegger, como a pessoa é um ser-no-mundo, a linguagem passa a ocupar um lugar de destaque, pois é alçada à categoria de condição de possibilidade do próprio mundo. Tal ocorre "porque é pela linguagem e somente por ela que podemos ter mundo e chegar a esse mundo. Sem linguagem não há mundo, enquanto mundo. Não há coisa alguma onde falta a pá-lavra. Somente quando se encontra a pá-lavra para a coisa é que a coisa é uma coisa". ${ }^{27}$ Para a interpretação desta linguagem, com o seu caráter fundante da própria existência do mundo, não se pode pensar numa hermenêutica ligada a métodos que buscam a única verdade ou certeza.

A existência do homem não é sempre igual, mas contingente. Com esta particularidade a hermenêutica deverá trabalhar, especialmente a partir da preocupação com os Direitos Humanos que são um norte para aquela proposta, mas afastando-se a pretensão de construir uma "resposta certa". Buscar-se-á, sempre, a melhor resposta tendo em vista as peculiaridades do caso concreto.

Nesse detalhe, a linguagem também é o meio para que se possa nominar e buscar os Direitos Humanos. Além do mais, a tradição e os demais estágios do tempo acima explicitados dependem da linguagem, como um caminho constituidor de sua existência. A linguagem é o elemento capaz de aproximar e relacionar as mais diversas culturas e as mais variadas formas de expressão dos Direitos humanos. 
Seguindo a esteira de Heidegger, Gadamer afirma: "O ser que pode ser compreendido é linguagem". ${ }^{28}$ A linguagem é o ser que pode ser compreendido. Significa dizer que somente poderemos conceber o ser do ente homem, a partir das possibilidades projetadas pela linguagem. A linguagem aponta para a totalidade do mundo onde ocorre a experiência da tradição. Entretanto, alerta Gadamer, "a tradição não é simplesmente um acontecer que se pode conhecer e dominar pela experiência, mas é linguagem, isto é, fala por si mesma, como faz um tu" ${ }^{29}$ A linguagem surge como a condição de possibilidade de toda experiência hermenêutica, ou seja, "é o medium universal em que se realiza a própria compreensão. A forma de realização da compreensão é a interpretação". ${ }^{30}$

A linguagem também se apresenta como uma condição anafastável para a significação dos diversos estágios do tempo planejados na obra de François Ost. Ela representa uma poderosa possibilidade para a construção de pontes que aproximam as diversas etapas. Paralelo a isso, também se mostra como suporte para a fala dos Direitos Humanos. E mais, para que as pessoas percebam a importância da linguagem, a fim de manter aberto um canal de comunicação à prática dos Direitos Humanos. A linguagem não é um instrumento que se coloca entre o sujeito e o objeto, a saber, entre a pessoa e os Direitos Humanos. Pelo contrário, é a partir dela que se pode concebê-los. Do mesmo modo, a tradição e suas possibilidades não estão dispostas para serem acessadas. Ela somente pode ser percebida e valorizada na e pela linguagem. No mesmo caminho vão os Direitos Humanos, isto é, eles somente têm a devida importância, pela mediação da linguagem.

A análise do tema aponta para um aspecto especial: "para que haja direitos humanos, é preciso existir um conceito universal de ser humano enquanto tal". ${ }^{31} \mathrm{~A}$ dificuldade para atender a essa exigência é grande. No entanto, se é levada em consideração a linguagem como a condição de possibilidade do mundo, também poderá ser atribuída a ela a viabilizadora de um elo de ligação das diversas culturas e ênfases acerca do ser humano. Parece que inexiste dúvida que o ser humano, como um ente relacional, busca a sua nominação pela linguagem. E é esse ser humano que luta por condições mínimas de existência. Além do mais, os Direitos Humanos se legitimam a partir de uma reciprocidade; de um intercâmbio. ${ }^{32}$ A linguagem mostra-se como esse elo que aproxima os seres humanos, posto que em todos, respeitando as diferenças, existe a necessidade de algumas condições mínimas de sobrevivência.

De certa maneira, essa caracterização servirá como norteador do exercício da autoridade por parte do Estado, seja interna ou externamente, "com o devido respeito aos direitos humanos que encarnam os requisitos da justiça e para o propósito de promover o bem comum no qual tal respeito pelos direitos é um componente". ${ }^{33}$ Promover o respeito aos Direitos Humanos acaba sendo uma obrigação pública ou um componente da atuação do Estado, posto em sintonia com a idéia de bem comum e de justiça. Vale destacar que esse respeito não pressupõe a previsão legal, eis que "os direitos humanos ou naturais são os direitos morais fundamentais e gerais". ${ }^{34}$ Portanto, esses direitos são algo mais 
profundo que um comando estatal; são, na verdade, um conteúdo essencial que justifica a própria estrutura de um Estado Democrático de Direito.

Tal característica pode ser examinada na fórmula de redação dos diversos documentos (Declarações) sobre Direitos Humanos. Todos empregam duas formas canônicas principais: "(a) Todos os indivíduos têm direito a ..." e "(b) Ninguém será ...", visando implantar as seguintes limitações: "(i) garantir o devido reconhecimento dos direitos e liberdades de outrem" e "(ii) satisfazer aos justos requisitos da moralidade, da ordem pública e do bem-estar geral em uma sociedade democrática". ${ }^{35}$

Os diversos compassos do tempo antes examinados formam-se a partir de vários elementos oriundos especialmente da tradição. Ao lado disso, a contribuição da perspectiva moral é inegável. Vislumbrando a situação por outro lado: a preocupação com a moral e a ética (sem considerar eventual distinção) acompanha a evolução humana, assim como a configuração dos seus direitos. Portanto, uma sociedade que desrespeita os Direitos Humanos, contraria um elemento valorativo - proveniente da ética e da justiça - que retira a legitimidade daquela atuação estatal.

Essas constatações mostram a universalidade dos Direitos Humanos e autoriza dizer: "independentemente da sociedade ou da época em que vive uma pessoa, esta deve possuir certos direitos somente pelo fato de ser pessoa." 6 A passagem aponta para a universalidade e o multiculturalismo que perpassam a noção de Direitos Humanos. Sublinhando: não há época histórica e nem grupo social, por mais peculiar que possa se apresentar, onde os "direitos" fiquem excluídos. Evidentemente que existem níveis e graus de valorização, próprios de cada modo de sociedade. No entanto, os "direitos" sempre estarão contemplados.

A linguagem e sua compreensão, interpretação e aplicação são percepções humanas. Quer dizer, presentes onde estiver uma pessoa que "é o homem não por sua substância, senão como uma reunião de relações no qual se encontra com respeito a seu mundo, a seus semelhantes e as coisas." 37 A pessoa é o ser do ente homem (e mulher) que se manifesta pela linguagem nas diversas relações, por isso "é a unidade imediatamente convivida do viver, mas não uma coisa simplesmente pensada fora e atrás do imediatamente vivido." ${ }^{38} \mathrm{O}$ ser pessoa leva o homem para vida, para o desenvolvimento do seu caráter social, sua abertura para o tempo, com ele aprendendo, ensinando, errando, enfim, vivendo e buscando os seus "direitos" por essa caracterização.

O ser pessoa do ente homem (e mulher) é a marca especial da universalidade dos Direitos Humanos. Para Antonio Cassese essa referência é um mito, eis "que a observância dos direitos humanos é muito diferente nos distintos países." " A universalidade não está vinculada às espécies de Direitos Humanos, mas à sua existência (talvez enquanto gênero). O certo é que as variadas espécies de Direitos Humanos estão vinculadas a fatores culturais. Portanto, não 
existe um padrão que caiba para todos, mas a todos deverá ser facultada a plena realização desses "direitos" dada a simples condição de titularidade humana.

Essa marca característica da presença de homens e mulheres não presos aos limites territoriais dos Estados, sublinha a sua complexidade, posto vinculados a um espaço global. Os Direitos Humanos surgem como um mecanismo de proteção contra os abusos cometidos pelos detentores do poder estatal. Não obstante, na atualidade, com a erosão do contexto estatal, a partir dos reflexos da globalização, surge um outro nível de preocupação: os Direitos Humanos deverão ser considerados para proteger homens e mulheres de um poder global, oriundo de várias frentes, sem uma origem bem definida.

Com isso, a luta volta-se novamente à busca de proteção a fim de construir "uma cultura dos direitos que recorra, em seu seio, à universalidade das garantias e ao respeito pelo diferente." 40 Tal contexto provoca, necessariamente, segundo Joaquín Herrera Flores, uma visão complexa dos Direitos Humanos, que deverá trabalhar com os olhos focados na periferia, objetivando examinar com possibilidade crítica o poder que domina o centro.

No caso, o poder econômico emanado dos grandes conglomerados internacionais, que surgem como uma nova "ameaça" aos Direitos Humanos. A periferia da qual fala Flores produz uma gama variada de ensinamentos: "quando não aprenderíamos sobre direitos humanos, escutando as histórias e narrações a respeito do espaço que habitamos expressadas por vozes procedentes de diferentes contextos culturais!" ${ }^{1}$ Deve-se, portanto, escutar a voz da tradição, onde já se está desde sempre inserido. Ela fornecerá subsídios ao respeito dos Direitos Humanos para todos os humanos, sem exceção.

Surge, com tal situação, uma nova face da universalidade dos Direitos Humanos, a "cidadania cosmopolita", onde os homens e mulheres não estão mais apenas em contato com a ordem jurídica do Estado nacional, mas sujeitos a uma ordem que vai além desse Estado. "A cidadania cosmopolita será, portanto, aquela que irá assegurar direitos e liberdades a serem reconhecidos, não somente pelo Estado nacional, mas que perpassará diversas ordens jurídicas. Será uma cidadania que se define não somente por um Estado, mas através de diferentes Estados." ${ }^{2}$ Os novos laços produzidos a partir da globalização continuam vinculados eticamente à concretização e respeito dos Direitos Humanos.

Mesmo dentro de um cenário com muitas peculiaridades, cada vez mais visível, o respeito aos Direitos Humanos precisa ser redesenhado "em função de três tipos de constatações empíricas, que obrigam a construção de um novo sistema de normas jurídicas: humanidade comum, ameaças compartilhadas e obrigações mínimas." ${ }^{43}$ Nesse conjunto de novos desafios, ocorre uma verdadeira simbiose entre o local e o global, ambos focados na construção de um arcabouço jurídico capaz de dar conta dos novos desafios, sem descuidar de um velho conjunto de "direitos". 
Além disso, Canotilho enfatiza que o desenvolvimento de uma "Constituição Nacional e um constitucionalismo global" exigirá a consideração dos "direitos humanos como limites morais ao pluralismo e às práticas sociais nacionais e internacionais". Isso porque "a 'lei' ou 'direito dos povos' não significa necessariamente direito internacional positivo, mas sim uma concepção política do direito e da justiça informadora dos princípios de direito e práticas internacionais." ${ }^{44}$ A principal face desse desafio não está na positivação dos "direitos", mas na explicitação de interesse político para que os Direitos Humanos efetivamente sejam respeitados, concretizados e colocados como justificativas éticas para a tomada das decisões que impliquem conseqüências humanas, consideradas em todas as suas dimensões (sociais, políticas, culturais, ecológicas, etc.).

A universalidade e o multiculturalismo próprios dos Direitos Humanos acabam refletindo um outro detalhe: o equacionamento de divergências em valores religiosos, culturais, filosóficos, jurídicos, morais, históricos, sociológicos e econômicos. ${ }^{45}$ Assim sendo, é correto observar que "o conteúdo dos Direitos Humanos traça, pois, um caminho que consiste em acoplar as diferentes sociedades numa ordem unitária universal que recolhe todos os direitos", formando uma 'societas universales' da humanidade. ${ }^{46}$

O projeto de realização dos Direitos Humanos será comandado pelos postulados do direito natural, ${ }^{47}$ formando um "novo direito natural da humanidade", inspirado "no sentido de um conjunto de parâmetros de conduta e avaliação, condizentemente filtrados - por obra de todos os Estados - de tradições ideológicas e filosóficas, de preceitos religiosos e concepções de mundo, e transformados pelos Estados mesmos em código internacional de conduta." ${ }^{38}$

Esta concepção dos Direitos Humanos inspira o surgimento de sistemas protetivos, conferindo aos homens e mulheres a categoria de "sujeito internacional", com outorga de direitos e deveres na órbita internacional ${ }^{49}$, gerando o chamado sistema normativo internacional de proteção, organizado no plano global (a Declaração Universal de Direito Humanos de 1948, por exemplo) ou no plano regional (Convenção Americana de Direitos Humanos de 1969 e Carta dos Direitos Fundamentais da União Européia de 2000, por exemplo).

\section{PROTEÇÃO \\ 3 O FIM DOS DIREITOS HUMANOS ${ }^{50}$ : DA FUNDAMENTAÇÃO À}

Norberto Bobbio refere que "o problema fundamental em relação aos direitos do homem, não é tanto o de justificá-los, mas o de protegê-los." ${ }^{11} \mathrm{Com}$ essa passagem, fica sublinhado que a busca por um fundamento para os Direitos Humanos não deverá ser o aspecto principal, mas a sua efetiva proteção. No fundo, a preocupação em fundamentar esses "direitos" liga-se ao contexto da existência de algum valor absoluto que possa sustentar os Direitos Humanos. 
Gregorio Robles afirma que existe a necessidade de fundamentar os Direitos Humanos, a qual não se circunscreve a um mero jogo intelectual, mas representa uma necessidade teórica e prática. Justifica o seu ponto de vista apontando a necessidade de saber-se o motivo da defesa de determinado assunto, de indicar o caminho a ser percorrido e o esclarecimento das idéias. ${ }^{52}$ Tudo indica que nenhum desses argumentos é suficiente e minimamente aceitável para se exigir a continuidade de propostas de fundamentação dos mencionados "direitos".

Alfredo Culleton também defende a necessidade da fundamentação, a partir de uma razão discursiva e não de autoridade: "a fundamentação racional dos direitos humanos não só é possível, mas também conveniente e necessária, dado que a base racional é a única que permite justificar plenamente a defesa dos valores jurídicos e políticos". Para tanto, propõe a seguinte fórmula: "toda fundamentação racional própria (isto é, coerente com seu peculiar caráter) tem uma validade racional absoluta". Apesar dessa caracterização, reconhece a abertura para que a sua validade não seja reconhecida por todos os envolvidos e nem limitada a qualquer consideração de tempo. ${ }^{53}$

Parafraseando Castanheira Neves pode-se dizer que essa postura é equivocada, na medida em que pretende resolver o problema da validade e fundamentação de um sistema mediante a concepção de outro sistema (este agora "fundamentante") a sobrepor o sistema dos Direitos Humanos a fundamentar. ${ }^{54} \mathrm{O}$ grande problema da busca de um fundamento é que ao chegarse até ele, se descobre que deve-se buscar outro, que esteja acima dele, e assim sucessivamente.

Hermeneuticamente falando isso não é possível e a preocupação oriunda dos Direitos Humanos não poderá ser submetida a tamanha cadeia de busca, sob pena de esquecer-se a sua proteção e implantação para todos os homens e mulheres. Tudo indica que a busca por um fundamento sempre resvala para uma "verdade absoluta" ou um ponto de partida igual e original que possa dar conta de todas as situações, além do desenvolvimento de um processo inferência. Entretanto, "é preciso ter claro que o sentido do ser de um ente não pode ser constitutivo do sentido do ser de outros entes." ${ }^{\text {"55 }}$ Nesse sentido, o sentido do ser da pessoa não poderá fornecer o sentido para os homens e mulheres e deles para os Direitos Humanos.

A análise das diversas etapas do tempo acima estudadas permite dizer a partir de Heidegger que ele (o tempo) é uma espécie de matriz e motor essencial da manifestação. Dentro dessa linha de idéias se pode constatar que o ser, como elemento de apoio a todo ente, "ele próprio não pode possuir um fundamento que por seu turno o justifique, pois tal conduziria a um processo de regressão infinito." 56 Nesse dilema resvala a procura por um fundamento para os Direitos Humanos. Não se pode aceitar o processo de inferência, dada a impossibilidade de se deduzir algo de algo. "Tampouco o fundamento pode ser uma frase, uma categoria. [...] Daí que, repita-se, o fundamento tem que ser 'sem fundo'. Ele é 
abissal, na medida em que nem é infinito e nem objetivo." ${ }^{57}$ Portanto, dentro da perspectiva da fenomenologia é necessário ter em consideração uma espécie de co-originalidade, que se manifesta nos "indícios formais". Sendo que eles "aparecem primeiramente e o mais das vezes de certo jeito, podendo ser usados para designar o ser humano."

Essa situação aponta para uma "espécie de passividade pela qual, desde sempre, já sei ser-jogado-no-mundo."59 Essa situação original se apresenta como um elemento hermenêutico da fenomenologia hermenêutica heideggeriana, que se mostra existencialmente a partir do mundo circundante onde cada homem e mulher já estão desde sempre inseridos. É por isso que se pode afirmar: os Direitos Humanos existem, porque desde sempre nos compreendemos como pessoa (ser) do ente homem ou mulher. Dessa feita, é a partir da diferença ontológica que emerge "um elemento não-inferencial, condição de possibilidade de qualquer inferência. A fenomenologia hermenêutica, através dos indícios formais, pretende abrir-nos 0 caminho para esse universo não-inferencial, o antepredicativo, que se dá em bases existenciais." ${ }^{60}$ É nessa perspectiva existencial que os indícios formais fundamentam através de um fundamento sem fundo, posto dependente do modo de ser do ser do Dasein, que, por essa característica, não se pode prender a um pressuposto lógico de regresso.

A preocupação com os Direitos Humanos é teleológica - de fim (a proteção) - e não de "início" - a fundamentação. Que os humanos têm "direitos" por serem humanos, ninguém duvida. A tradição, formada pelo enlaçamento dos diversos estágios do tempo com a mediação da linguagem, testemunha nesse sentido. O grande problema é a efetivação dos Direitos Humanos, aí a preocupação, que deverá estar focada na realização humana integral, a partir do seguinte aspecto: "os direitos do homem não são somente inalienáveis, mas também, com todo rigor, invioláveis" ${ }^{\text {. }}$. Essa é a tônica da situação atual sobre os Direitos Humanos.

Portanto, no seio de um Direito Constitucional Internacional é preciso alocar a principal obrigação de todos os Estados: a proteção dos Direitos Humanos. Além disso, é necessário um rigor maior nos órgãos jurisdicionais, responsáveis pelas demandas que envolvam esses "direitos".

Serve de exemplo, portanto, a seguinte manifestação nesse sentido: “[...] 8. Que, em virtude da responsabilidade do Estado de adotar medidas de segurança para proteger as pessoas que estejam sujeitas a sua jurisdição, a Corte estima que este dever é mais evidente ao se tratar de pessoas reclusas em um centro de detenção estatal, em cujo caso se deve presumir a responsabilidade estatal no que aconteça às pessoas que se encontram sob sua custódia. 9. Que no Direito Internacional dos Direitos Humanos as medidas provisórias têm um caráter não só cautelar, no sentido de que preservam uma situação jurídica, senão fundamentalmente tutelar, porquanto protegem direitos humanos. Sempre que se reúnam os requisitos básicos da extrema gravidade e urgência e da prevenção de 
danos irreparáveis às pessoas, as medidas provisórias se transformam em uma verdadeira garantia jurisdicional de caráter preventivo. [...]." ${ }^{62}$

Aqui fica reconhecido que o Estado tem responsabilidade na sua conduta, com vistas à proteção dos Direitos Humanos em relação aos homens e mulheres que estão sob sua jurisdição. No caso, o Brasil tem o dever de assegurar a vida digna e condições mínimas para a garantia da humanidade daqueles que vivem em seu território. Aí o rumo da preocupação: a efetividade aos "direitos". Tal conclusão está assegurada pela Constituição Federal quando, no art. 1ํ, III, estabelece uma das bases do Estado Democrático de Direito brasileiro na dignidade da pessoa humana. Ela, por si só, é o elemento de sustentação dos Direitos Humanos. Vale dizer, a dignidade da pessoa humana é a expressão mais clara do respeito aos Direitos Humanos. Além do mais, o texto constitucional reconhece que a "prevalência dos direitos humanos" é um dos princípios que rege o Brasil nas suas relações internacionais (art. 4, II).

A preocupação constitucional brasileira sobre essa matéria recebeu um importante aliado pela Emenda Constitucional (EC) no 45/2004, quando introduziu mais um inciso ao art. 109, da CF, atribuindo a competência ao Juiz Federal para julgar "as causas relativas a direitos humanos". Nessa mesma EC, por via da introdução do $\S 5$, ao citado art. 109, conferiu ao Procurador-Geral da República a competência para suscitar, perante o Superior Tribunal de Justiça, em qualquer fase do inquérito ou processo, incidente de deslocamento de competência para a Justiça Federal, quando se tratar de grave violação de direitos humanos. Têm-se, com isso, sinais concretos de uma preocupação efetiva com a proteção dos direitos dos humanos que vivem no Brasil. Caberá, portanto, à Justiça Federal, valendo-se das possibilidades hermenêuticas, atribuir o sentido mais coerente para que essa matéria efetivamente receba o tratamento pretendido pelo legislador constituinte.

Acrescente-se a tais "avanços" o conteúdo do § $3^{\circ}$, do art. 5, da CF/88, que assegura aos tratados e convenções sobre direitos humanos, aprovados com o quorum ali especificado (aprovação, em cada Casa do Congresso Nacional, em dois turnos, por três quintos dos votos dos respectivos membros), a categoria de "emendas constitucionais".

Essa possibilidade, na prática, gera alguns inconvenientes: a categoria de emenda constitucional, para ser retirada do ordenamento jurídico, exige um procedimento especial. Isso poderá ser um problema, a partir do momento em que ocorra a denúncia do tratado pelo Brasil. Além disso, aprovada a emenda constitucional, o tratado passará a ter vigência na ordem interna. No caso da ordem externa, o tratado pode ainda não ter reunido o número suficiente de subscrições. Com isso, não teria vigência, ainda. Nesse caso, o tratado já seria obrigatório na órbita interna, mas ainda não na externa. Outra discussão que o mencionado parágrafo tem suscitado está relacionado aos tratados anteriores. Qual a sua categoria? Embora o Supremo Tribunal Federal entenda que os tratados referentes a direitos humanos têm o 'status' de legislação ordinária, 
parece inaceitável tal posição, pois os direitos humanos representam um dos princípios fundamentais da Constituição Federal. Assim, apenas por isso, essa matéria deveria ocupar o escalão de norma constitucional, a inspirar toda a produção normativa do ordenamento jurídico. ${ }^{63}$

Apesar dessas reservas, com tais providências constitucionais, se dará aplicação ao princípio da dignidade da pessoa humana, mostrando que o Estado Democrático de Direito no Brasil está cumprindo as promessas inscritas na Carta Magna de 1988.

Essa preocupação nacional deverá ganhar corpo na esfera mundial, a partir da chamada "competência compartilhada" sobre esse tema, com o respeito à soberania de cada Estado. A mencionada competência deverá ter condição para trabalhar com "a multiplicidade das normas combinando unificação e harmonização, mas também o pluralismo dos Estados e da sociedade democrática". Quer dizer, combinar as diferenças de cada cultura, assentada no elemento humano comum. É preciso, no entanto, atentar para o seguinte desafio:

\begin{abstract}
ordenar o pluralismo determinando os limites, as fronteiras que devem restar intransponíveis, porque franqueá-las significaria destruir a própria idéia de humanidade. Essas fronteiras, que alguns buscam como o 'conteúdo último do direito natural', são já traçadas pelos direitos inderrogáveis, mas, ainda mais diretamente agora, pela noção de 'crime contra humanidade', ou do patrimônio comum da 'humanidade'. ${ }^{4}$
\end{abstract}

É necessário, portanto, um empenho interno e externo de cada Estado, a fim de, respeitando a diversidade cultural, implementar o verdadeiro caráter universal dos Direitos Humanos, dando-lhes o verdadeiro sentido de um "direito natural global". Somente dessa forma se poderá continuar falar em humanidade. $\mathrm{O}$ alerta está dado: não há avanço tecnológico ou científico que substitua a preocupação com o humano, pois nada tem sentido se o principal objetivo não estiver calcado nesse ingrediente.

Essa tarefa, no entanto, não cabe exclusivamente aos Estados. Pelo contrário, cada homem e mulher têm a obrigação de contribuir e cada àqueles propiciar e incentivar essa participação nesse compromisso que é de todos. Nasce, com isso, o "princípio da subsidiaridade":

da mesma forma como é errado retirar do indivíduo e confiar a um grupo o que a iniciativa privada e o esforço podem realizar, é uma injustiça [...] para uma associação maior e superior apropriar-se indevidamente de funções que podem ser realizadas eficientemente por associações menores e inferiores. [...] $O$ verdadeiro objetivo, por sua própria natureza, de toda atividade social deve ser ajudar membros de um corpo social, nunca destruir ou absorvê-los (Pio XI, Encíclica Quadragesimo Anno-1931). ${ }^{65}$

O conteúdo desse princípio será fundamental para que se possa construir uma autêntica política de Direitos Humanos. Não se trata de dar essa atribuição exclusivamente aos Estados, inviabilizando a participação dos particulares 
(homens e mulheres). Todos deverão ser convocados a participar, objetivando compor um lugar mais digno para cada humano viver. A reunião de pequenos, médios e grandes grupos auxiliando cada Estado a fazer a sua parte é um ingrediente poderoso para que possa construir o verdadeiro sentido dos Direitos Humanos, onde cada um dos participantes escolhe uma tarefa para executar.

A aplicação do "princípio da subsidiaridade" pode ser verificada numa das decisões tomadas pelo Tribunal Europeu de Direitos Humanos ${ }^{66}$, ao julgar os delitos cometidos pelos soldados da fronteira, quando mataram diversas pessoas que tentavam cruzar a fronteira da então República Democrática Alemã. Os fatos ocorreram entre 1949 e 1961. Para tentar controlar a onda de fugitivos, a República Democrática Alemã construiu o Muro de Berlim e reforçou todas as medidas de segurança ao longo da fronteira entre os dois Estados alemães, instalando minas antipessoais e sistemas de disparo automático.

O Tribunal entendeu que uma prática estatal como a política de polícia de fronteira viola flagrantemente os direitos humanos e especialmente o direito à vida, que é o valor supremo na hierarquia internacional dos direitos humanos e representa um atributo inalienável dos seres humanos. Caso a República Democrática Alemã ainda existisse, ela seria responsabilizada desde o ponto do direito internacional. Por outro lado, houve responsabilidade penal individual dos integrantes do pólo ativo do processo, os quais, além da violação dos instrumentos internacionais de proteção dos direitos humanos, também transgrediram o art. 95, do Código Penal da República Democrática Alemã, ao expressar, já em 1968, "que existiria uma responsabilidade penal individual de todo aquele que violasse as obrigações internacionais da República Democrática Alemã, ou os direitos humanos e as liberdades fundamentais"

A situação de fato e de direito que está subjacente nesse julgado, deixa marcado que em matéria de Direitos Humanos há responsabilidade dos Estados e também dos seus nacionais. Aí a subsidiaridade. Desta feita, é preciso deixar que homens ou mulheres e cada Estado experienciem, ajam e participem, dentro das suas condições, para que se proteja no mais alto nível os direitos dos humanos. Para tanto, torna-se fundamental escutar a voz da tradição e da experiência, formada pelos diversos compassos do tempo, enlaçados pelo poder constitutivo e constituinte da linguagem, como uma poderosa alternativa para que os direitos dos humanos efetivamente ganhem a merecida proteção de todos e todas, pois a investigação sobre o seu fundamento é sem fundo e, apesar disso, recebeu a devida atenção por um longo percurso histórico.

É chegado o momento de transferir-se o foco para a proteção, a fim dos humanos perceberem a eficácia dos seus "direitos", abandonando os pré-juízos inautênticos vinculados à associação dos Direitos Humanos ao Direito Natural, mediante a valorização de ambos como um produto histórico onde a vida em sociedade está desde sempre inserida. Outro pré-juízo inautêntico está voltado à idéia de que os Direitos Humanos são ocidentais. Sobre esse tema, Ângela Kretschmann refere: 
Apesar de sua origem ocidental, hoje são do mundo, não podendo ser
dito que correspondem a um produto tipo exportação, uma vez que na
atualidade são o melhor instrumento que civilizações não ocidentais
possuem para impedir ações que coloquem em risco sua
autodeterminação. ${ }^{68}$

Como não se poderá mais trabalhar com a visa ocidentalizada dos Direitos Humanos, o multiculturalismo apresenta-se como o elemento nuclear para a sua concretização. Assim, projeta-se um contexto necessário para que os Direitos Humanos sejam focados na sua efetiva implantação, posto que já fundamentados. Como espaço privilegiado de discussão acerca da dignidade da pessoa humana, os Direitos Humanos deverão perpassar a construção de um Direito que quer permanecer em sintonia com um mundo globalizado e cada vez mais interligado. Com isso, fica evidenciado que

a recente evolução tende mais largamente a inserir os direitos do homem na duração, com direitos de 'solidariedade' que situam o indivíduo em relação à sua linhagem (ascendentes e descendentes) e a coletividade em relação às gerações futuras, portanto à espécie ou à 'família' humana. ${ }^{69}$

A efetividade dos Direitos Humanos aponta para um detalhe muitas vezes esquecidos: são direitos de todos os humanos, sem exceção. Embora sejam de todos, não buscam uma uniformização das pessoas. Pelo contrário, o grande desafio é o respeito das diferenças. Essas representam o fator multicultural que o Direito precisa aprender a respeitar e trabalhar. Isso aponta mais um aspecto relacionado à efetividade dos Direitos Humanos, em busca um pensamento focado no múltiplo.

\section{CONCLUSÃO}

O enlaçamento dos diversos espaços temporais aponta para uma necessária leitura dos Direitos Humanos numa perspectiva múltipla. Tais espaços mostram o aprendizado com as experiências futuras e a possibilidade do "eterno retorno". Esses espaços deverão ser aproveitados para a construção de alternativas de efetividade dos direitos dos humanos.

A linguagem mostra-se como uma condição de possibilidade para a construção desses espaços e viabilizar o diálogo entre todos os envolvidos. O "fim dos direitos humanos" deverá ser interpretado num sentido teleológico, ou seja, não é a sua conclusão ou extinção, mas a sua finalidade. Para tanto, deverá preponderar o princípio da subsidiaridade, envolvendo a todos. Não é responsabilidade somente dos Estados, mas também de cada pessoa.

Tudo indica que o grande desafio da humanidade, apesar de todo o avanço científico e tecnológico, continua sendo o respeito dos Direitos Humanos. Ainda não se aprendeu a colocar a pessoa em primeiro lugar e o foco principal das 
reflexões e das ações. Entretanto, pela análise desenvolvida, existem várias iniciativas para retirar os Direitos Humanos do plano teórico - muito vinculado à fundamentação - e colocá-los no plano da prática e da efetividade das ações tomadas pelos Estados e particulares.

\section{TRADITION AND LANGUAGE AS CONDITIONS OF POSSIBILITY TO AN UNIVERSAL AND MULTICULTURAL PERSPECTIVE OF HUMAN RIGHTS}

\footnotetext{
ABSTRACT

This work will investigate the importance of time, specially through different stages proposed by François Ost. This analysis is enforced by contributions from hermeneutic of Martin Heideger and Hans-Georg Gadamer. In this context, it intends to show that language is condition of possibility to assimilate this tradition in order to project the universality and multiculturalism of Human Right, mainly in the 21 st Century.

Keywords: Hermeneutic. Human Rights. Language. Multiculturalism. Phlisophical Tradition. Universalism.

\section{NOTAS}

* Doutor e Mestre em Direito pelo Programa de Pós-Graduação em Direito da Unisinos/RS; Professor de Direitos Humanos no Mestrado do mesmo Programa; Líder do Grupo de Pesquisa JUSNANO (CNPq/Unisinos); Professor de Método Jurídico e Metodologia da Pesquisa Jurídica em diversos Cursos de Especialização em Direito da Unisinos; Professor de Introdução ao Estudo do Direito do Curso de Graduação em Direito da Unisinos; Integrante da Comissão de Coordenação do Curso de Graduação em Direito da Unisinos e Advogado.

1 HEIDEGGER, Martin. Die Grundprobleme der Phänomenologie. Frankfurt an Main: Vittorio Klostermann, 1975, Band 24, p. 351.

2 OST, François. O Tempo do Direito. Tradução de Maria Fernanda Oliveira. Lisboa: Instituto Piaget, 1999, p. 54.

3 Ibidem, p. 63-4.

4 MACINTYRE, Alasdair. Justiça de quem? Qual racionalidade? Tradução de Marcelo Pimenta Marques. 2. ed. São Paulo: Loyola, 2001, p. 382.

5 OST, François. Op. Cit., p. 64.

6 Ibidem, mesma página.

7 GADAMER, Hans-Georg. Verdade e Método I: traços fundamentais de uma hermenêutica filosófica. Tradução de Flávio Paulo Meurer. 4. ed. Petrópolis: Vozes, 2002, p. 442.

8 Idem. Esboço dos fundamentos de uma hermenêutica. IN: FRUCHON, Pierre (Org.). $O$ problema da consciência histórica. Tradução de Paulo César Duque Estrada. Rio de Janeiro: Fundação Getúlio Vargas, 1998, p. 67-8.

9 PALMER, Richard E. Hermenêutica. Tradução de Maria Luísa Ribeiro Ferreira. Lisboa: Edições 70, 1996, p. 180.

10 OST, François. Op. Cit., p. 65.

11 Ibidem, p. 67.
} 
12 Ibidem, p. 156.

13 Segundo Heidegger, "a tarefa preliminar de se assegurar 'fenomenologicamente' o acesso ao ente exemplar como ponto de partida da própria analítica já se acha sempre delineada a partir do próprio ponto de chegada" (HEIDEGGER, Martin. Ser e Tempo. Tradução de Marcia Sá Cavalcante Schuback. 12. ed. Petrópolis: Vozes, 2002, Parte I, § 7, p. 68). É olhando para frente, com os olhos postos na tradição, que será possível construir a compreensão do mundo circundante.

14 HEIDEGGER, Martin. Ser e Tempo. Tradução de Marcia Sá Cavalcante Schuback. 10. ed. Petrópolis: Vozes, 2002. Parte II, § 65, p. 120.

15 OST, François. Op. Cit., p. 203.

16 Ibidem, p. 206.

17 HEIDEGGER, Martin. Ser e Tempo. Tradução de Marcia Sá Cavalcante Schuback. 12. ed. Petrópolis: Vozes 2002, Parte I, § 32, p. 204 et seq.

18 OST, François. Op. Cit., p. 216.

19 Ibidem, p. 219.

$20 \quad$ Ibidem, p. 227.

21 GADAMER, Hans-Georg. Verdade e Método II. Tradução de Enio Paulo Giachini. Petrópolis: Vozes, 2002, p. 79.

22 OST, François. Op. Cit., p. 319.

23 Ibidem, p. 347.

24 HEIDEGGER, Martin. Ser e Tempo. Tradução de Marcia Sá Cavalcante Schuback. 10. ed. Petrópolis: Vozes, 2002, Parte II, § 65, p. 120.

25 OST, François. Op. Cit., p. 350.

26 HEIDEGGER, Martin. Ser e Tempo. Op. Cit., Parte II, § 59, p. 79.

27 STRECK, Lenio Luiz. Jurisdição Constitucional e Hermenêutica: Uma Nova Crítica do Direito. 2. ed. rev. e ampl. Rio de Janeiro: Forense, 2004, p. 204-5.

28 GADAMER, Hans-Georg. Verdade e Método I: traços fundam entais de uma hermenêutica filosófica. Tradução de Flávio Paulo Meurer. 4. ed. Petrópolis: Vozes, 2002, p. 687.

$29 \quad$ Ibidem, p. 528.

$30 \quad$ Ibidem, p. 566.

31 HÖFFE, Otfried. Derecho intercultural. Tradução de Rafael Sevilla. Barcelona: Gedisa, 2000, p. 194.

32 Ibidem, p. 201.

33 FINNIS, John Mitchell. Lei natural e direitos naturais. Tradução de Leila Mendes. São Leopoldo: Unisinos, 2007, p. 35.

$34 \quad$ Ibidem, p. 195.

35 Ibidem, p. 207 e 209.

36 HÖFFE, Otfried. Op. Cit., p. 179.

37 KAUFMANN, Arthur. El Renacimiento del Derecho Natural de la Posguerra y lo que fue de él. Tradução do alemão de Alejandra Guardia Clausi. IN: CABANILLAS, Renato Rabbi-Baldi (Coord.). Las razones del derecho natural: perspectivas teóricas y metodológicas ante la crisis del positivismo jurídico. Buenos Aires: Editorial Abaco de Rodolfo Depalma, 2000, p. 248. SCHELER, Max. Ética: nuevo ensayo de fundamentación de un personalismo ético. Tradução de Hilário Rodríguez Sanz. Buenos Aires: Revista de Occidente Argentino, 1948, p. 159.

39 CASSESE, Antonio. Los derechos humanos en el mundo contemporâneo. Tradução de Atílio Pentimalli y Blanca Ribera de Madariaga. Barcelona: Ariel, 1993, p. 61.

40 FLORES, Joaquín Herrera. Direitos humanos, interculturalidade e racionalidade da resistência. Tradução de Carol Proner. IN: WOLKMER, Antonio Carlos (Org.). Direitos humanos e filosofia jurídica na América Latina. Rio de Janeiro: Lumen Juris, 2004, p. 365.

41 Ibidem, p. 368.

42 BARRETTO, Vicente de Paulo. Globalização, Direito Cosmopolítico e Direitos Humanos. IN: Revista do Instituto de Hermenêutica Jurídica - Direito, Estado e Democracia: entre a (in)efetividade e o imaginário social. Porto Alegre: Instituto de Hermenêutica Jurídica, v. 1, n. 4, p. 411-30, 2006, p. 419-20.

43 Ibidem, p. 425. 
CANOTILHO, José Joaquim Gomes. Estudos sobre Direitos Fundamentais. 1. ed. bras. 2. ed. port. São Paulo: RT; Portugal: Coimbra Editora, 2008, p. 135.

45 MIRANDA, Jorge. A recepção da Declaração Universal dos Direitos do Homem pela Constituição Portuguesa - um fenômeno de conjugação de Direito Internacional e Direito Constitucional. Revista de Direito Administrativo. Rio de Janeiro, n. 199, p. 1-20, jan./mar. 1995. p. 9 e GUERRERO, Pedro Francisco Gago. Presupuestos para una posible puesta en prática universal de los derechos humanos. IN: Revista de Estudios Políticos. Madrid: Centro de Estudios Políticos y Constitucionales, n. 111, p. 65-99, jan./mar. 2001, p. 71.

GUERRERO, Pedro Francisco Gago. Presupuestos para una posible puesta en prática universal de los derechos humanos. IN: Revista de Estudios Políticos. Madrid: Centro de Estudios Políticos y Constitucionales, n. 111, p. 65-99, jan./mar. 2001, p. 88 e 90.

47 ENGELMANN, Wilson. Direito Natural, Ética e Hermenêutica. Porto Alegre: Livraria do Advogado, 2007, p. 135 et seq.

48 CASSESE, Antonio. Op. Cit., p. 227.

49 PIOVESAN, Flávia. Introdução ao sistema interamericano de proteção dos direitos humanos: A convenção americana de direitos humanos. IN: GOMES, Luiz Flávio e PIOVESAN, Flávia (Coord.). O sistema interamericano de proteção dos direitos humanos e o direito brasileiro. São Paulo: Revista dos Tribunais, 2000, p. 33 e PIOVESAN, Flávia. Direitos Humanos e o Direito Constitucional Internacional. São Paulo: Max Limonad, 1996 p. 19.

50 Título adaptado a partir da obra de DOUZINAS, Costas. The end of human rights: critical legal thought at the turn of the century. Oxford: Hart Publishing, 2000.

51 BOBBIO, Norberto. A era dos direitos. Tradução de Carlos Nelson Coutinho. 8. ed. Rio de Janeiro: Campus, 1992, p. 24.

52 ROBLES, Gregorio. Los derechos fundamentales y la ética en la sociedad actual. Madrid: Civitas, 1995, p. 11 et seq.

53 CULLETON, Alfredo. Por que e onde buscar um princípio fundador para os direitos humanos? IN: Revista Estudos Jurídicos, São Leopoldo, v. 40, n. 2, p. 57-9, jul./dez. 2007, p. 58 et seq.

54 CASTANHEIRA NEVES, A. Curso de Introdução ao Estudo do Direito. Coimbra: João Abrantes, 1971-72, p. 59.

55 STRECK, Lenio Luiz. Jurisdição Constitucional e Hermenêutica: Uma Nova Crítica do Direito. 2. ed. rev. e ampl. Rio de Janeiro: Forense, 2004, p. 227.

56 BLANC, Mafalda Faria. O Fundamento em Heidegger. Lisboa: Instituto Piaget, 1998, p. 141.

57 STRECK, Lenio Luiz. Op. Cit., 2004, p. 227.

58 STEIN, Ernildo. Pensar é Pensar a Diferença: filosofia e conhecimento empírico. ljuí: Unijuí, 2002, p. 160.

59 Ibidem, mesma página.

$60 \quad$ Ibidem, p. 168.

61 FINNIS, John Mitchell. Lei Natural: Por que chamar de "lei"? Por que dizê-la "natural"? Tradução de Magda Lopes. IN: CANTO-SPERBER, Monique (Org.). Dicionário de Ética e Filosofia Moral. São Leopoldo: Unisinos, 2003, vol. 2, p. 42.

62 Resolução da Corte Interamericana de Direitos Humanos de 18 de junho de 2002, no pedido de Medidas Provisórias solicitadas pela Comissão Interamericana de Direitos Humanos a Respeito do Brasil em favor dos internos da Casa de Detenção José Mario Alves - conhecida como "Penitenciária Urso Branco", localizada na cidade de Porto Velho, Estado de Rondônia, com o objetivo de evitar que continuem a morrer internos na penitenciária. (MELLO, Celso D. de Albuquerque e TORRES, Ricardo Lobo (Dir.). Arquivos de Direitos Humanos. Rio de Janeiro: Renovar, 2003, vol. 5, p. 258).

63 Sobre o tema, consultar: SARLET, Ingo Wolfgang. A Reforma do Judiciário e os Tratados Internacionais de Direitos Humanos: algumas notas sobre 0 novo $\S 3^{0}$ do art. $5^{0}$ da Constituição. IN: Direito, Estado e Democracia: entre a (in)efetividade e o imaginário social. Revista do Instituto de Hermenêutica Jurídica. Porto Alegre: Instituto de Hermenêutica Jurídica, v. 1, n. 4, p. 183-200, 2006.

64 DELMAS-MARTY, Mireille. Três Desafios para um Direito Mundial. Tradução de Fauzi Hassan Choukr. Rio de Janeiro: Lúmen Júris, 2003, p. 169.

65 FINNIS, John Mitchell. Lei natural e direitos naturais. Tradução de Leila Mendes. São Leopoldo: Unisinos, 2007. p. 159. 
66 Caso Streletz, Kessler e Krenz v. Alemanha, petições no 34044/96, 35532/97 e 44801/98; Estrasburgo, em 22 de março de 2001.

67 VIGO, Rodolfo Luis. La injusticia extrema no es derecho: (de Radbruch a Alexy). Buenos Aires: La Ley, 2004, p. 101 et seq.

68 KRETSCHMANN, Ângela. Universalidade dos Direitos Humanos e Diálogo na Complexidade de um Mundo Multicivilizacional. Curitiba: Juruá, 2008, p. 391.

69 DELMAS-MARTY, Mireille. Por um direito comum. Tradução de Maria Ermantina de Almeida Prado Galvão. São Paulo: Martins Fontes, 2004, p. 182.

\section{REFERÊNCIAS}

BARRETTO, Vicente de Paulo. Globalização, Direito Cosmopolítico e Direitos Humanos. IN: Revista do Instituto de Hermenêutica Jurídica - Direito, Estado e Democracia: entre a (in)efetividade e o imaginário social. Porto Alegre: Instituto de Hermenêutica Jurídica, v. 1, n. 4, p. 411-30, 2006.

BLANC, Mafalda Faria. O Fundamento em Heidegger. Lisboa: Instituto Piaget, 1998.

BOBBIO, Norberto. A era dos direitos. Tradução de Carlos Nelson Coutinho. 8. ed. Rio de Janeiro: Campus, 1992.

CANOTILHO, José Joaquim Gomes. Estudos sobre Direitos Fundamentais. 1. ed. bras. 2. ed. port. São Paulo: RT; Portugal: Coimbra Editora, 2008.

CASSESE, Antonio. Los derechos humanos en el mundo contemporâneo. Tradução de Atílio Pentimalli y Blanca Ribera de Madariaga. Barcelona: Ariel, 1993.

CASTANHEIRA NEVES, A. Curso de Introdução ao Estudo do Direito. Coimbra: João Abrantes, 1971-72.

CULLETON, Alfredo. Por que e onde buscar um princípio fundador para os direitos humanos? IN: Revista Estudos Jurídicos, São Leopoldo, v. 40, n. 2, p. 57-9, jul./dez. 2007.

DELMAS-MARTY, Mireille. Três Desafios para um Direito Mundial. Tradução de Fauzi Hassan Choukr. Rio de Janeiro: Lúmen Júris, 2003.

Por um direito comum. Tradução de Maria Ermantina de Almeida Prado Galvão. São Paulo: Martins Fontes, 2004.

DOUZINAS, Costas. The end of human rights: critical legal thought at the turn of the century. Oxford: Hart Publishing, 2000.

ENGELMANN, Wilson. Direito Natural, Ética e Hermenêutica. Porto Alegre: Livraria do Advogado, 2007.

FINNIS, John Mitchell. Lei Natural: Por que chamar de "lei"? Por que dizê-la "natural"? Tradução de Magda Lopes. IN: CANTO-SPERBER, Monique (Org.). Dicionário de Ética e Filosofia Moral. São Leopoldo: Unisinos, 2003, vol. 2. 
Lei natural e direitos naturais. Tradução de Leila Mendes. São Leopoldo: Unisinos, 2007.

FLORES, Joaquín Herrera. Direitos humanos, interculturalidade e racionalidade da resistência. Tradução de Carol Proner. IN: WOLKMER, Antonio Carlos (Org.). Direitos humanos e filosofia jurídica na América Latina. Rio de Janeiro: Lumen Juris, 2004.

GADAMER, Hans-Georg. Verdade e Método I: traços fundamentais de uma hermenêutica filosófica. Tradução de Flávio Paulo Meurer. 4. ed. Petrópolis: Vozes, 2002.

Vozes, 2002a.

Verdade e Método II. Tradução de Enio Paulo Giachini. Petrópolis:

Esboço dos fundamentos de uma hermenêutica. IN: FRUCHON, Pierre (Org.). O problema da consciência histórica. Tradução de Paulo César Duque Estrada. Rio de Janeiro: Fundação Getúlio Vargas, 1998.

GUERRERO, Pedro Francisco Gago. Presupuestos para una posible puesta en prática universal de los derechos humanos. IN: Revista de Estudios Políticos. Madrid: Centro de Estudios Políticos y Constitucionales, n. 111, p. 65-99, jan./mar. 2001.

HEIDEGGER, Martin. Die Grundprobleme der Phänomenologie. Frankfurt an Main: Vittorio Klostermann, 1975, Band 24.

. Ser e Tempo. Tradução de Marcia Sá Cavalcante Schuback. 12. ed. Petrópolis: Vozes, 2002. Parte I.

. Ser e Tempo. Tradução de Marcia Sá Cavalcante Schuback. 10. ed. Petrópolis: Vozes, 2002a. Parte II.

HÖFFE, Otfried. Derecho intercultural. Tradução de Rafael Sevilla. Barcelona: Gedisa, 2000.

KAUFMANN, Arthur. El Renacimiento del Derecho Natural de la Posguerra y lo que fue de él. Tradução do alemão de Alejandra Guardia Clausi. IN: CABANILLAS, Renato Rabbi-Baldi (Coord.). Las razones del derecho natural: perspectivas teóricas y metodológicas ante la crisis del positivismo jurídico. Buenos Aires: Editorial Ábaco de Rodolfo Depalma, 2000.

KRETSCHMANN, Ângela. Universalidade dos Direitos Humanos e Diálogo na Complexidade de um Mundo Multicivilizacional. Curitiba: Juruá, 2008.

KRETSCHMANN, Ângela. Universalidade dos Direitos Humanos e Diálogo na Complexidade de um Mundo Multicivilizacional. Curitiba: Juruá, 2008.

MACINTYRE, Alasdair. Justiça de quem? Qual racionalidade? Tradução de Marcelo Pimenta Marques. 2. ed. São Paulo: Loyola, 2001.

MELLO, Celso D. de Albuquerque e TORRES, Ricardo Lobo (Dir.). Arquivos de Direitos Humanos. Rio de Janeiro: Renovar, 2003, vol. 5. 
MIRANDA, Jorge. A recepção da Declaração Universal dos Direitos do Homem pela Constituição Portuguesa - um fenômeno de conjugação de Direito Internacional e Direito Constitucional. Revista de Direito Administrativo. Rio de Janeiro, n. 199, p. 1-20, jan./mar. 1995.

OST, François. O Tempo do Direito. Tradução de Maria Fernanda Oliveira. Lisboa: Instituto Piaget, 1999.

PALMER, Richard E. Hermenêutica. Tradução de Maria Luísa Ribeiro Ferreira. Lisboa: Edições 70, 1996.

PIOVESAN, Flávia. Introdução ao sistema interamericano de proteção dos direitos humanos: A convenção americana de direitos humanos. IN: GOMES, Luiz Flávio e PIOVESAN, Flávia (Coord.). O sistema interamericano de proteção dos direitos humanos e o direito brasileiro. São Paulo: Revista dos Tribunais, 2000.

- Direitos Humanos e o Direito Constitucional Internacional. São Paulo: Max Limonad, 1996.

ROBLES, Gregorio. Los derechos fundamentales y la ética en la sociedad actual. Madrid: Civitas, 1995.

SARLET, Ingo Wolfgang. A Reforma do Judiciário e os Tratados Internacionais de Direitos Humanos: algumas notas sobre o novo $\S 3^{\circ}$ do art. $5^{\circ}$ da Constituição. IN: Direito, Estado e Democracia: entre a (in)efetividade e o imaginário social. Revista do Instituto de Hermenêutica Jurídica. Porto Alegre: Instituto de Hermenêutica Jurídica, v. 1, n. 4, p. 183-200, 2006.

SCHELER, Max. Ética: nuevo ensayo de fundamentación de un personalismo ético. Tradução de Hilário Rodríguez Sanz. Buenos Aires: Revista de Occidente Argentino, 1948.

STEIN, Ernildo. Pensar é Pensar a Diferença: filosofia e conhecimento empírico. ljuí: Unijuí, 2002.

STRECK, Lenio Luiz. Jurisdição Constitucional e Hermenêutica: Uma Nova Crítica do Direito. 2. ed. rev. e ampl. Rio de Janeiro: Forense, 2004.

VIGO, Rodolfo Luis. La injusticia extrema no es derecho: (de Radbruch a Alexy). Buenos Aires: La Ley, 2004.

Recebido para publicação 14/11/2008

Aceito para publicação 13/01/2009 
